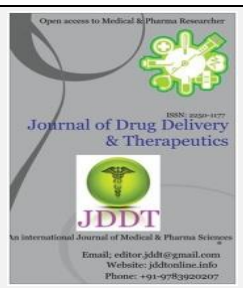

Open $\odot$ Access

Research Article

\title{
Evaluation of Mosquito Larvicidal Activity of Ethanolic Extract of Grewia flavescens Juss. Whole Plant (Family: Tiliaceae) Against Culex quinquefasciatus
}

\author{
Dr. G.N. Pramodini1*, Dr. Parwez Alam², Dr. Mohd Rafiq ${ }^{3}$, Dr. Shaik mohd Khasim ${ }^{4}$ \\ ${ }^{1}$ Associate professor, Department of pharmacognosy, Shadan college of pharmacy, Peerancheeru, Hyderabad-500091, Telangana, India. \\ 2 Associate professor, Department of pharmacognosy, Shadan college of pharmacy, Peerancheeru, Hyderabad-500091, Telangana, India. \\ ${ }^{3}$ Associate professor, Department of pharmacognosy, Shadan college of pharmacy, Peerancheeru, Hyderabad-500091, Telangana, India. \\ ${ }^{4}$ Director, Shadan College of pharmacy, peerancheeru, Hyderabad-500091, Telangana, India.
}

\begin{abstract}
To evaluate the mosquito larvicidal activity on the ethanolic extract of Grewia flavescens juss (EEGF). Whole plant against Culex quinquefasciatus larvae. The larval mortality of 4 th instar larvae of Culex quinquefasciatus after $24 \mathrm{~h}$ and $48 \mathrm{~h}$ of treatment which were tested separately in control and five test concentrations of 125 ppm, 250 ppm, 500 ppm,750 ppm, 1000 ppm concentration. The plant extract was screened to identify phytochemical bioactive compounds like alkaloids, flavonoids, saponins, tannins and glycosides. Different concentration of crude ethanolic extract of Grewia flavescensjuss. whole plant effectively showed larvicidal activity on Culex quinquefasciatus larvae. Based on the probit analysis values for $24 \mathrm{~h}$ and $48 \mathrm{~h}$ ethanolic extract of Grewia flavescens shows pronounced larvicidal activity. The LC 50 and LC 90 values of EEGF against mosquito 4th instar larvae of Culex quinquefasciatus was found 223.87 ppm and 724.43 ppm at $24 \mathrm{hrs}$ and for $48 \mathrm{hrs}$ the LC 50 and LC 90 values was found to be $181.97 \mathrm{ppm}$ and $374.76 \mathrm{ppm}$ respectively. The preliminary phytochemical was performed in search of plants secondary metabolites which might be responsible for the larvicidal activity. The bioactive phytochemical classes which were identified and confirmed as alkaloids, flavonoids, saponins, tannins and glycosides. The ethanolic extract of this plant showed potent larvicidal activity and can be considered for further investigation. This experimental study was a pioneer attempt to establish Grewia flavescens juss. as a valuable resource of effective target specific natural mosquito larvicide.
\end{abstract}

Keywords: Culex quinquefasciatus, larvicidal activity, ethanolic ext., phytochemical.

Article Info: Received 12 July 2019; Review Completed 18 Aug 2019; Accepted 22 Aug 2019; Available online 30 Aug 2019

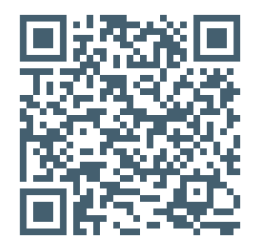

\section{Cite this article as:}

Pramodini GN, Alam P, Rafiq M, Khasim SM, Evaluation of Mosquito Larvicidal Activity of Ethanolic Extract of Grewia flavescens Juss. Whole Plant (Family: Tiliaceae) Against Culex quinquefasciatus, Journal of Drug Delivery and Therapeutics. 2019; 9(4-A):252-255 http://dx.doi.org/10.22270/jddt.v9i4-A.3467

Dr. G.N. Pramodini, Associate professor, Department of pharmacognosy, Shadan college of pharmacy, Peerancheeru, Hyderabad-500091, Telangana, India.

\section{1) INTRODUCTION:}

Mosquitoes are the carriers of many diseases such as malaria, dengue fever, yellow fever, filariasis etc. They are responsible for the death and illness of millions of people through the transmission of diseases. ${ }^{1}$ In most developing countries of the tropical and subtropical regions of the world, mosquitoes constitute as the foremost vectors of several debilitating diseases affecting human and domestic animals. $^{2}$

Culex quinquefasciatus mosquitoes, belonging to one of the disease transmitting mosquito genera. ${ }^{3}$ Culex quinquefasciatus is a vector of lymphatic filariasis that is endemic in many countries in Africa, South Asia, The pacific island and the american worldwide, an estimated 20 million peoples are affected by lymphatic filariasis, with above one third of their suffering from hydrocele or lymphedema. ${ }^{4}$ Breeding in polluted water such as blocked drains, damages septic tanks, soak age ponds close to human habitations. ${ }^{5}$

Mosquito control is a difficult task, due to a variety of factors including the development of insecticide resistant in target population. The high cost of new insecticides and concern over environmental pollution. While it is likely that chemical insecticides will continue to be required for mosquito control so, an increased emphasis is being placed all over the world on the development of suitable alternatives to control vector borne diseases ${ }^{6}$. Many plant based products are 
widely used for their insecticidal and repellent properties for the control of mosquitos.7,8 Grewia flavescens (Tiliaceae) popularly known as "donkeys berry", is a shrub or small tree, often seen in groups along the edges of roads, river banks and dry rivers, growing in large uniform groups. The plant parts are being used in Indian folk medicine. The leaves were reported to be useful in ulcerated tongue, colic pain, wounds, cholera and dysentery. Grewia flavescens is a multistemmed shrub or small tree, up to $5 \mathrm{~m}$ high. Its bark is dark grey-brown belongs to Tiliaceae family. The plant is used as Anthelmentic ${ }^{9}$, CNS depressant, anti-inflammatory ${ }^{10}$, antimalarial, antidiabetic ${ }^{11}$ and analgesic in Indian traditional system of medicine. The berries of Grewia flavescens are soaked in water for two or three days to make a refreshing drink. Based on the traditional claim as in olden days the plant is used as an antimalarial agent so, we tried to expedite to cheek for the larvicidal activity of Grewia flavescens juss whole plant against Culex quinquefasciatus mosquito larvae.

\section{2) MATERIALS AND METHODS:}

\section{1). Plant collection and authentication:}

The crude Grewia flavescens juss. whole plant was collected from Sri Venkateshwara univesity, Titupathi, Andhra pradesh, India. The plant was authenticated with plant voucher specimen no. 1397, by plant taxonomist Dr. K Madhava chetty, Assisstant professor, Department of botany, Sri Venkasteshwara university, Tirupathi, Andhra pradesh, India.

\section{2) Preparation of plant extract:}

The fresh whole plant of Grewia flavescens juss. were collected in the month of december from Tirupathi, India. The whole plant Grewia flavescens juss was washed with tap water, shade dried for two weeks, and pulverized. Then passed through sieve number 60 and stored in an air tight container.

About $1000 \mathrm{~g}$ of powered drug extracted with $80 \%$ ethanol by using maceration method of extraction. The method is followed until the phytoconstituents were completely exhausted. The ethanolic extract was evaporated through rotary evaporator under reduced pressure at $40^{\circ} \mathrm{C}$ and labeled as EEGF $6.2 \%$ yield and preserved at $5^{\circ} \mathrm{C}$ in airtight container until further use.

\section{3) Phytochemical screening:}

The phytochemical screening was carried out as described by harbone ${ }^{12}$. By this analysis, the prescence of several phytochemical listed in Table 3 was tested.

\section{4) Selection of mosquito species and cultures:}

The mosquito species selected for the present study was culex quinquefasciatus, its larval form were collected from mosquito genic region of chandrayangutta, Hyderabad. This larvae were collected in the month of march 2019 on the filter paper and kept in the specimen box. Collected larvae were numbered, recorded and identified by Dr. Deepa jaiswal scientist D zoologist, zoological survey of india. They identified it as larvae of culex quinquefasciatus say, 1823 (commonly known as the southern house mosquito). The larvae were fed on larval food powdered dog biscuit and yeast in the ratio $3: 1.13$

\section{5). Larvicidal Bioassay:}

The plant extrat was established in ethanol and diluted with distilled water to give 2000 ppm stock solution with tween 80 kept at concentration of $1 \%$. Different concentration of $125,250,500,750,1000 \mathrm{ppm}$ were prepared from the stock solution. The bioassay tests were conducted according to a standard WHO procedure (1981) with slight modifications. The bioassay was carrid on $4^{\text {th }}$ instar stage larvae, six groups were made including controlled solution with each group containing 25 larvae. The larvae were placed in $100 \mathrm{ml}$ beaker of test solution and fed on powdered cat food during all testing. Larvae were considered dead if they were unarousable even when gently prodded. The dead larvae were counted after $24 \mathrm{~h}$ and $48 \mathrm{~h}$ and percentage mortality for each concentration were calculated. The control solution used in this experiment is distilled water.

\section{6) Larval Susceptibility test:}

The larval susceptibility tests were carried according to standard WHO procedure. The extract solutions of different concentrations were prepared and larvae of Culex quinquefasciatus were placed in each test solution to observe the larvicidal property as per the following procedure.

Group of 25 larvae were placed in $200 \mathrm{ml}$ of the extract solution. Control experiments without extract were run in parallel. The larvae in each solution were then left for $24 \mathrm{~h}$ and $48 \mathrm{~h}$ and the number of dead larvae were counted after $24 \mathrm{~h}$ and $48 \mathrm{~h}$ of exposure, and the percentage mortality was reported from the average of five replicates. Mortality was recorded when control mortality ranged from 5-20 percent, it was corrected by using Abbott's formula. ${ }^{14}$

\section{3) Data Analysis}

All the collected data is analysed using probit analysis and $\mathrm{LC}_{50}$ and $\mathrm{LC}_{90}$ were calculated. A graph

TABLE 1: Effect of EEGF whole plant on Culex quinquefasciatus $4^{\text {th }}$ instar larvae $(24 \mathrm{~h})$.

\begin{tabular}{|c|c|c|c|c|c|c|}
\hline $\begin{array}{c}\text { Exposure } \\
\text { time in } \\
\text { hours }\end{array}$ & Conc. (PPM) & $\begin{array}{c}\text { Log } \\
\text { Conc. }\end{array}$ & $\begin{array}{c}\text { Number of } \\
\text { larvae } \\
\text { exposed }\end{array}$ & $\begin{array}{c}\text { Number of } \\
\text { deaths }\end{array}$ & \% death & Probit \\
\hline $24 \mathrm{hrs}$ & $\mathrm{C}(00)$ & - & 25 & - & - & - \\
\hline $24 \mathrm{hrs}$ & 125 & 2.09 & 25 & 8 & 32 & 4.53 \\
\hline $24 \mathrm{hrs}$ & 250 & 2.39 & 25 & 12 & 48 & 4.95 \\
\hline $24 \mathrm{hrs}$ & 500 & 2.69 & 25 & 18 & 72 & 5.58 \\
\hline $24 \mathrm{hrs}$ & 750 & 2.87 & 25 & 23 & 92 & 6.41 \\
\hline $24 \mathrm{hrs}$ & 1000 & 3 & 25 & 24 & 96 & 6.75 \\
\hline
\end{tabular}




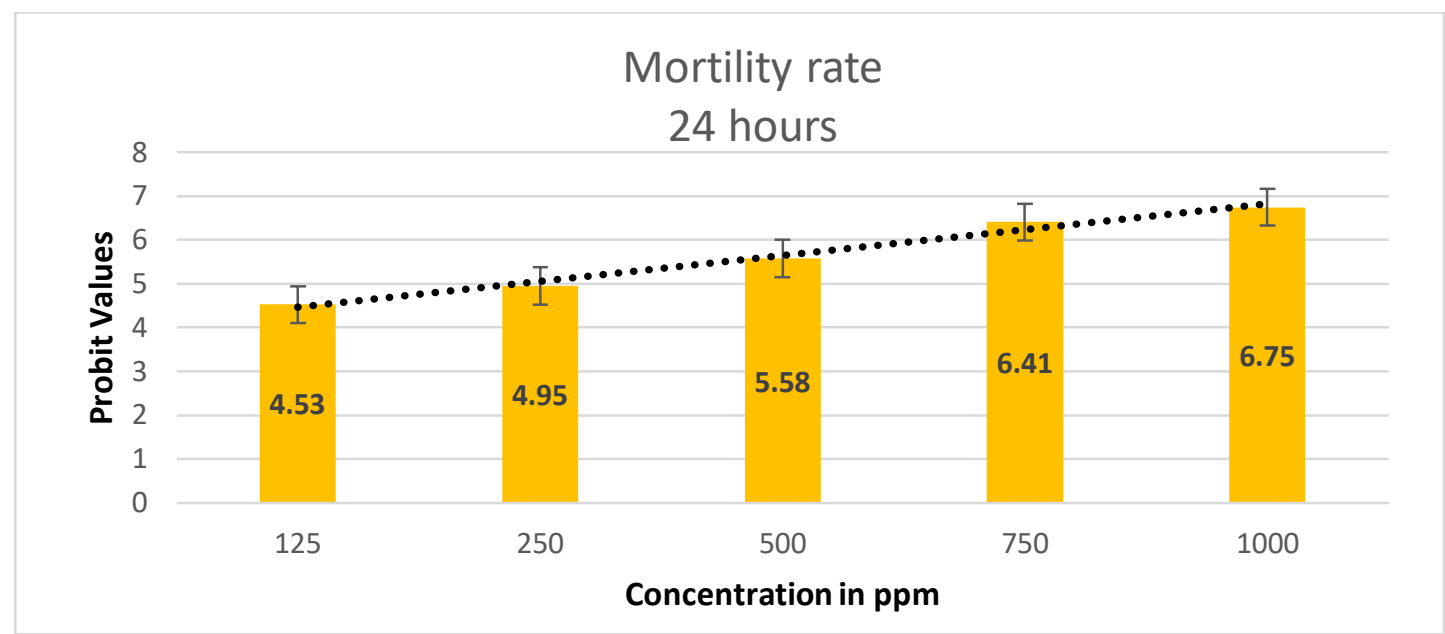

GRAPH 1: Graphical presentation of probabilities of larvicidal activity of EEGF at different concentrations (24h)

TABLE 2:Effect of EEGF whole plant on Culex quinquefasciatus $4^{\text {th }}$ instar larvae (48 h).

\begin{tabular}{|c|c|c|c|c|c|c|}
\hline $\begin{array}{c}\text { Exposure } \\
\text { time in } \\
\text { hours }\end{array}$ & $\begin{array}{c}\text { Conc. } \\
\text { (PPM) }\end{array}$ & $\begin{array}{c}\text { Log } \\
\text { Conc. }\end{array}$ & $\begin{array}{c}\text { Number of } \\
\text { Larvae } \\
\text { Exposed }\end{array}$ & $\begin{array}{c}\text { Number of } \\
\text { deaths }\end{array}$ & \% deaths & Probit \\
\hline $48 \mathrm{hrs}$ & $\mathrm{C}(00)$ & - & 25 & - & - & - \\
\hline $48 \mathrm{hrs}$ & 125 & 2.09 & 25 & 12 & 48 & 4.95 \\
\hline $48 \mathrm{hrs}$ & 250 & 2.39 & 25 & 16 & 64 & 5.3 \\
\hline $48 \mathrm{hrs}$ & 500 & 2.69 & 25 & 20 & 80 & 5.84 \\
\hline $48 \mathrm{hrs}$ & 750 & 2.87 & 25 & 24 & 96 & 6.75 \\
\hline $48 \mathrm{hrs}$ & 1000 & 3 & 25 & 25 & 100 & 10 \\
\hline
\end{tabular}

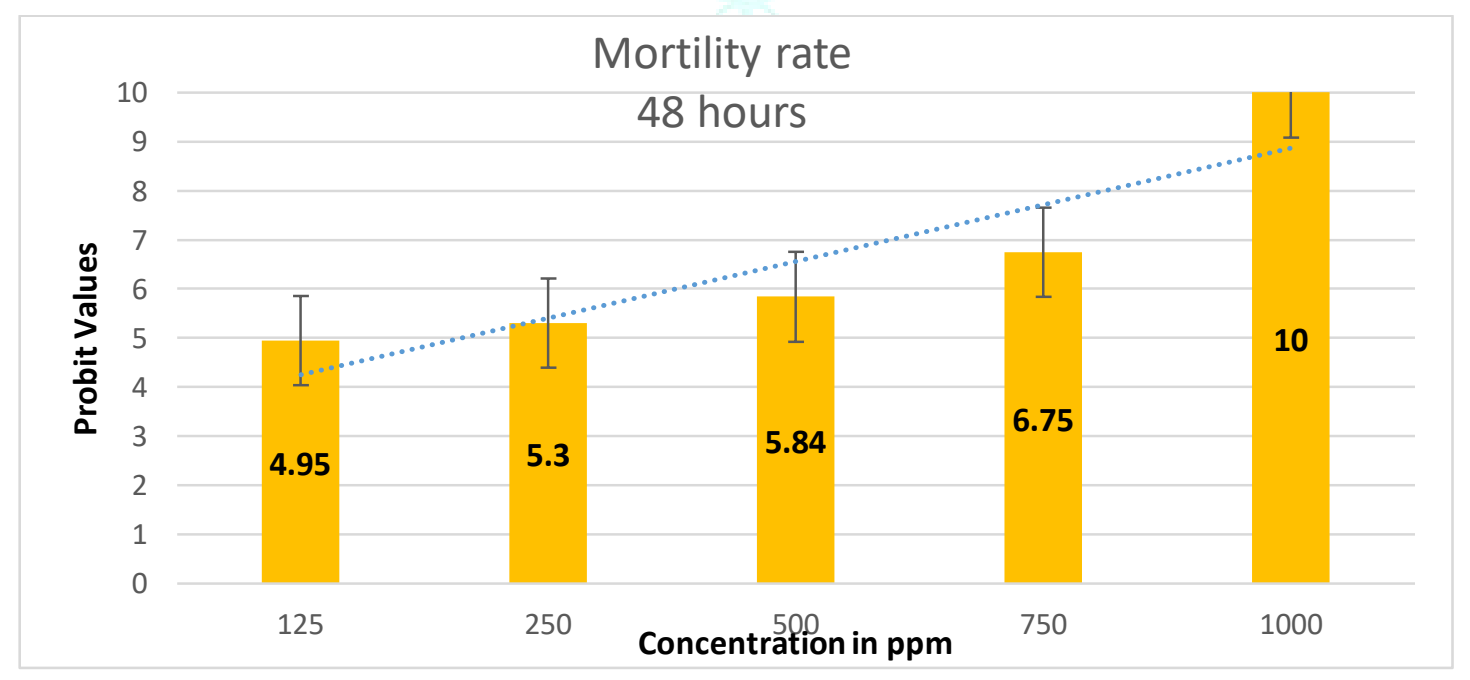

GRAPH 2: Graphical presentation of probabilities of larvicidal activity of EEGF at different concentrations (48h).

\subsection{Statistical Analysis}

The concentration at which mortality observed (ppm) was corrected using Abbott's formula. ${ }^{14}$ Statistical analysis of the experimental data was performed with MS-Excel 2007 to find the standard deviation and $\mathrm{LC}_{50}$ and $\mathrm{LC}_{90}$ using Probit analysis. 


\section{4) RESULTS AND DISSUCSSION:}

\subsection{LETHAL CONCENTRATIONS ( $\mathrm{LC}_{50} \& \mathrm{LC}_{90}$ )}

TBALE 4: Lethal concentrations of whole plant extract of Grewia flavescens Juss. against fourth instar larvae of Culex quinquefasciatus.

\begin{tabular}{|c|c|c|c|c|c|c|c|c|c|c|c|}
\hline \multirow{3}{*}{ 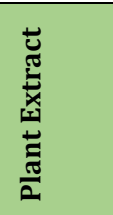 } & \multirow{3}{*}{ 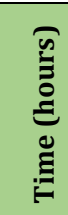 } & \multirow{3}{*}{ 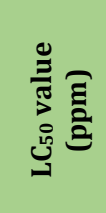 } & \multirow{3}{*}{ 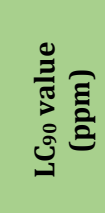 } & \multirow{3}{*}{\multicolumn{2}{|c|}{ 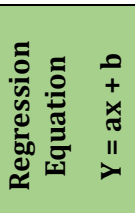 }} & \multicolumn{4}{|c|}{ 95\% Confidence limit } & \multirow{3}{*}{ 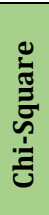 } & \multirow{3}{*}{$\begin{array}{c}\text { P- } \\
\text { Value }\end{array}$} \\
\hline & & & & & & \multicolumn{2}{|c|}{ UCL(ppm) } & \multicolumn{2}{|c|}{ LCL(ppm) } & & \\
\hline & & & & & & $\begin{array}{l}\text { LC }_{50} \\
\text { ppm }\end{array}$ & $\begin{array}{l}\text { LC90 } \\
\text { ppm }\end{array}$ & $\begin{array}{ll}C_{50} & \text { LC } \\
\text { ppm } & \text { pr }\end{array}$ & & & \\
\hline 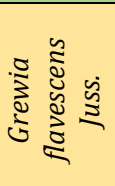 & 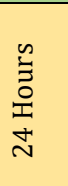 & $\begin{array}{l}\hat{\infty} \\
\text { ஸ் } \\
\text { N }\end{array}$ & $\begin{array}{l}\stackrel{m}{+} \\
\stackrel{+}{N}\end{array}$ & 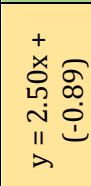 & & 246.94 & 747.5 & 212.95 & 713.51 & ğ & 0.36 \\
\hline 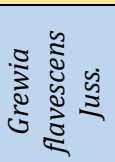 & 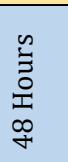 & 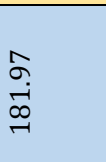 & $\begin{array}{l}\frac{0}{N} \\
\frac{+}{n}\end{array}$ & 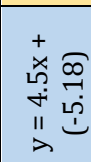 & & 206.15 & 398.94 & 167.36 & 360.15 & $\stackrel{m}{\sim}$ & 0.41 \\
\hline
\end{tabular}

The qualitative phytochemical screening of Grewia flavescens juss. were done to detect the presence of various chemical constituents, the ethanolic extract of Grewia flavescens gave positive test for various phytoconstituents such as Steroids. Flavonoids, Alkaloids, Tannins, Saponins etc.

The $\mathrm{LC}_{50}$ and $\mathrm{LC}_{90}$ for ethanol extract of Grewia flavescens juss. against 4th instarlarvae of Culex quinquefasciatus after $24 \mathrm{~h}$ post treatment were $223.87 \mathrm{ppm}$ and724.43 ppm respectively and after $48 \mathrm{~h}$ exposure were $181.7 .897 \mathrm{ppm}$ and 374.76ppm (Table 4).

\section{5) CONCLUSION:}

The Grewia flavescens whole plant ethanolic extract had showed significant larvicidal activity that was carried out on fourth instar stagelarvae of culex quinquefasciatus, the $\mathrm{LC}_{50}$ and $\mathrm{LC}_{90}$ values were calculated for time period of $24 \mathrm{~h}$ and $48 \mathrm{~h}$ thereby, increased in the larval mortality was observed. Hence, we confirmed that the plant under study Grewia flavescens juss. whole plant is a herb having an alternate source of herbal larvicidal agent, it is considered to be safe, easily available, economic and most importantly an effective against larvae of Culex quinquefasciatus. The above findings justified the traditional claim for the larvicidal activity of this plant Grewia flavescens juss. possess a good larvicidal activity which is proven scientifically in a well systemic manner.

\section{ACKNOWLEDGEMENT:}

The authors are grateful to Dr. Shaik mohd khasim the director of Shadan College of pharmacy, peerencheeru, Hyderabad, for providing infrastructure and facilities to carry out our research work.

\section{REFERENCES:}

1. Deepika T, Ramanibai R, Madhavarani A, 2014, mosquito larvicidal activity of coriandrumsativum and brasssica nigra seed extract againts the filarial vector; culex quinquefasciatussay, Int J Innov Res Sci Eng Technol; 3(1); 8632-8.
2. Reuda L.M., 2008, Global diversity of mosquitoes (Insect: Diptera: Calicidae) in freshwater, Developments in hydriobiology, 198;477-487.

3. Olayemi Israel kayode et.al., 2017, Larvicidal activities of lea extracts of adansania digitataL.(Malvales:Valvaceae ) and ficus sur forssk (Rosales : Moraceae). Againts Culexquinquefasciatus mosquitoes (Diptera ; culicidae ); 7(15) ;115-124.

4. Michael E, Bundy DA, Grenfell BT, 1996, Re- assessing the global prevalence and distributionof lymphatic filariasis,Parasitology ,112:409-28.

5. Holder P., 1999 The mosquitoes of New Zealand and their animal disease significance.Surveillance; 26(4):12-15.

6. Vinod Krishan; Jyothi nitey et.al., 2008 Evaluation of mosquito laricidal activity of Bioactivesaponine isolated from tridex procumbens linn ( family : Asteraceae) against Aedes aegypti. Int.j.chem. sci, 6(3), 1504-1510.

7. Savannce promsiri, Amara Naksathi, maleeya kruatrachue and usaradee thavara, 2006, Evaluation of larvicidal activity of medicinal plant extract on non-target fish, Insect science, 13,179 .

8. Young Su Jang, Ju Hyun and Hoi Seon Lee (2005), Mosquito larvicidal activity constituentderived from chamaecyparis Obtusa leaves against three mosquito species. J. Amer.mosq.cont.Assoc., 21, 400.

9. Pramodini GN, Dr. Shaik mohammed khasim 2018, evaluation of anthelmintic activity of ethanolic extract of grewia flavescens juss whole plant. Wjpps Volume 7, Issue 4, 9981003.

10. Nadkarni K.M., 1996, Indian material medica, vol-1, page-489.

11. G.N.Pramodini and Dr.K.Appanna howdary (2017), study of acute and anti-inflammatory activity of ethanolic extract of Grewia flavesecns juss whole plant using in rats. European journal of pharmaceutical and medical research., vol.,4[4], 595-599.

12. Harborne, J. B. (1973). Phytochemical methods: A guide to modern techniques of plant analysis. Chapman and Hall Ltd, London.; Pp. 279.

13. Arivoli, S., Samuel, T., 2011. Bioefficacy of Citrullus colocynthis (L.) Schrad (cucurbitaceae) whole plant extracts against Anopheles stephensi, Aedes aegypti and Culex quinquefasciatus (Dipters: Culicidae). Int. J. Curr. Res. 3, 296-304.

14. Abbott, W.S., 1925. A method of computing the effectiveness of an insecticide. J. Econ. Entomol. 18, 265-267. 